\title{
Predictors of severe H1N1 infection in children presenting within Pediatric Emergency Research Networks (PERN): retrospective case-control study
}

\author{
(c) $(1)$ (8)
}

\begin{abstract}
Stuart R Dalziel paediatrician ${ }^{12}$, John MD Thompson senior research fellow ${ }^{2}$, Charles G Macias associate professor ${ }^{3}$, Ricardo M Fernandes paediatrician ${ }^{4}$, David W Johnson professor ${ }^{5}$, Yehezkel Waisman professor $^{6}$, Nicholas Cheng paediatrician ${ }^{7}$, Jason Acworth paediatrician ${ }^{8}$, James M Chamberlain professor ${ }^{9}$, Martin H Osmond professor ${ }^{10}$, Amy Plint associate professor ${ }^{10}$, Paolo Valerio paediatrician $^{11}$, Karen JL Black paediatrician ${ }^{12}$, Eleanor Fitzpatrick research coordinator ${ }^{12}$, Amanda S Newton assistant professor ${ }^{13}$, Nathan Kuppermann professor ${ }^{14}$, Terry P Klassen professor $^{15}$, for the Pediatric Emergency Research Networks (PERN) H1N1 working group
\end{abstract}

\footnotetext{
${ }^{1}$ Starship Children's Hospital, Auckland, New Zealand; ${ }^{2}$ University of Auckland, Auckland, New Zealand; ${ }^{3}$ Baylor College of Medicine and Texas Children's Hospital, Houston, TX, USA; ${ }^{4}$ Department of Pediatrics, Hospital de Santa Maria, and Laboratory of Clinical Pharmacology and Therapeutics, Faculty of Medicine, Instituto de Medicina Molecular, Lisboa, Portugal; ${ }^{5}$ Alberta Children's Hospital Research Institute, University of Calgary, Calgary, AB, Canada; ${ }^{6}$ Schneider Children's Medical Center of Israel, Petach Tikvah, Israel; ${ }^{7}$ The Children's Hospital at Westmead, Sydney, NSW, Australia; ${ }^{8}$ Royal Children's Hospital, Brisbane, Qld, Australia; ${ }^{9} \mathrm{Children's} \mathrm{National} \mathrm{Medical} \mathrm{Center,} \mathrm{Washington} \mathrm{DC,} \mathrm{USA;}{ }^{10}$ University of Ottawa and Children's Hospital of Eastern Ontario, Ottawa, ON, Canada; ${ }^{11}$ Onze Lieve Vrouwe Gasthuis, Amsterdam, Netherlands; ${ }^{12}$ IWK Health Centre, Halifax, NS, Canada; ${ }^{13}$ University of Alberta, Edmonton, AB, Canada; ${ }^{14}$ Departments of Emergency Medicine and Pediatrics, University of California, Davis School of Medicine, Davis, CA, USA; ${ }^{15}$ Manitoba Institute of Child Health, University of Manitoba, Winnipeg, MB, Canada
}

\begin{abstract}
Objective To identify historical and clinical findings at emergency department presentation associated with severe H1N1 outcome in children presenting with influenza-like illness.

Design Multicentre retrospective case-control study.

Setting 79 emergency departments of hospitals associated with the Pediatric Emergency Research Networks in 12 countries.

Participants 265 children ( $<16$ years), presenting between 16 April and 31 December 2009, who fulfilled Centers for Disease Control and Prevention criteria for influenza-like illness and developed severe outcomes from laboratory confirmed $\mathrm{H} 1 \mathrm{~N} 1$ infection. For each case, two controls presenting with influenza-like illness but without severe outcomes were included: one random control and one age matched control.

Main outcome measures Severe outcomes included death or admission to intensive care for assisted ventilation, inotropic support, or both. Multivariable conditional logistic regression was used to compare cases and controls, with effect sizes measured as adjusted odds ratios.

Results 151 (57\%) of the 265 cases were male, the median age was 6 (interquartile range 2.3-10.0) years, and 27 (10\%) died. Six factors were
\end{abstract}

associated with severe outcomes in children presenting with influenza-like illness: history of chronic lung disease (odds ratio 10.3, 95\% confidence interval 1.5 to 69.8 ), history of cerebral palsy/developmental delay (10.2, 2.0 to 51.4 ), signs of chest retractions (9.6, 3.2 to 29.0), signs of dehydration (8.8, 1.6 to 49.3$)$, requirement for oxygen $(5.8,2.0$ to 16.2$)$, and tachycardia relative to age).

Conclusion These independent risk factors may alert clinicians to children at risk of severe outcomes when presenting with influenza-like illness during future pandemics.

\section{Introduction}

In June 2009 the World Health Organization declared the first global influenza pandemic in 41 years. ${ }^{1}$ From early in the pandemic, children-particularly those aged under 5 years ${ }^{2}$ - were considered a population at higher risk of morbidity and mortality from pandemic H1N1 (pH1N1) infection. ${ }^{1}$

Several studies from around the world have included children and adults admitted to hospital or intensive care units with pH1N1 infection. ${ }^{3-18}$ However, these data vary in format and 
emphasis, making direct comparison between studies difficult. Furthermore, data on severe outcomes (including death) and risk factors for severe outcomes are limited. One large multi-country analysis identified that risk for severe outcomes was associated with eight pre-existing medical conditions; unfortunately, data for paediatric and adult patients were combined, making conclusions specific to children difficult to formulate. $^{19}$

During the pandemic, emergency departments and primary care facilities experienced large surges of children presenting with influenza-like illness. ${ }^{20-22}$ These surges corresponded to influxes of $\mathrm{pH} 1 \mathrm{~N} 1$ related admissions to intensive care units. To date, no reports have detailed which factors in children with influenza-like illness and $\mathrm{pH} 1 \mathrm{~N} 1$ infection at presentation to emergency departments are associated with a risk of progression to severe disease or death. Such information would be highly relevant for informing emergency department and primary care clinicians regarding risk stratification, resource allocation, and clinical disposition in future pandemics.

We did this study to identify historical and clinical findings at presentation to emergency departments associated with severe outcomes of $\mathrm{pH} 1 \mathrm{~N} 1$ infection in children presenting with influenza-like illness. To answer this question on a global scale, we studied children presenting to the emergency departments of hospitals associated with the Pediatric Emergency Research Networks (PERN) ${ }^{23}$ PERN comprises representative hospitals from the five major paediatric emergency medicine research networks located in Europe, the Middle East, North America, and Australasia. Together, the five research networks have access to data from more than three million paediatric emergency department presentations annually, from more than 100 hospitals, in four of the six WHO regions.

\section{Methods}

We did a retrospective case-control study of children ( $<16$ years) who presented with influenza-like illness to 79 emergency departments in 12 countries between 16 April and 31 December 2009, during the $2009 \mathrm{H} 1 \mathrm{~N} 1$ pandemic.

\section{Participants}

Cases-Cases were children who fulfilled the Centers for Disease Control and Prevention (CDC) criteria for influenza-like illness at emergency department presentation (fever measured at home or hospital (temperature $\geq 37.8^{\circ} \mathrm{C}$ or $\geq 100^{\circ} \mathrm{F}$ ) and either cough or sore throat), ${ }^{22}$ who subsequently died or were admitted to an intensive care unit for assisted ventilation, inotropic/vasopressor support, or both (defined as severe outcomes) as a result of laboratory confirmed pH1N1 infection. Laboratory confirmation was either by polymerase chain reaction or viral culture. We excluded patients as cases if they were admitted directly into an intensive care unit from a hospital that was not a study site (because emergency department documentation and controls were not available), did not fulfil CDC criteria for influenza-like illness in the emergency department, or had suspected $\mathrm{pH} 1 \mathrm{~N} 1$ infection that was not confirmed by laboratory testing, as defined above.

Controls-For each case, we identified two controls who presented with influenza-like illness to the same emergency department but who did not develop severe outcomes: one random control and one age matched control. The random control was the patient presenting most proximately before the case who fulfilled the CDC criteria for influenza-like illness. The age matched control was the patient presenting most proximately after the case who fulfilled the CDC criteria for influenza-like illness and who was in the same age group as the case ( $<2$ years, 2 to $<5$ years, 5 to $<10$ years, 10 to 15 years). Patients were eligible as controls independently of hospital admission or laboratory testing for $\mathrm{pH} 1 \mathrm{~N} 1$ infection.

Severe H1N1 without influenza-like illness in emergency department (WILIE) group-The study also included children with laboratory confirmed $\mathrm{pH} 1 \mathrm{~N} 1$ infection with severe outcomes as defined above, but who do not meet the CDC criteria for influenza-like illness in the emergency department. We included this additional group of patients only if they had presented to a study site's emergency department. We identified these patients to assess accurately the proportion of severely affected patients with $\mathrm{pH} 1 \mathrm{~N} 1$ infection who present to emergency departments without influenza-like illness and to document treatment and outcome data for all patients with severe $\mathrm{pH} 1 \mathrm{~N} 1$ infection. We did not include this group in the primary case-control analysis.

We identified potential cases, controls, and WILIE patients at individual hospitals by a combination of searching intensive care unit, emergency department, laboratory, and mortality databases. Confirmation of inclusion in the study was determined by detailed review of patient medical records.

\section{Data collection}

We collected data for all patient groups according to standard methods for retrospective chart reviews. ${ }^{24}$ Site investigators (all physicians) used a detailed manual of operations with all variables defined a priori. Variables were defined according to pre-specified standard international definitions. A data source hierarchy was pre-specified for all data points. Data included premorbid history, patient's history at clinical presentation, physical examination, laboratory/radiographic investigations, management, and outcome. For reasons of feasibility, site investigators were not masked to outcome or case/control status.

We used the Pediatric Risk of Admission Score, second generation (PRISA II), to measure severity of illness at emergency department presentation. ${ }^{25}$

\section{Analysis}

We evaluated the univariable association of clinical risk factors with severe outcomes both between the cases and the random controls and between the cases and the age matched controls. We did conditional logistic regression analyses allowing for matching by site for the cases and the random controls and allowing for matching by site and age for the cases and the age matched controls. We did these analyses to determine possible variables for inclusion in multivariable models, as well as to delineate better the effect of age. For the $11 \%$ of cases with multiple emergency department visits, we used variables from the first recorded visit. We created multivariable models by using the same conditional logistic regression analyses. We created models by using a two step process to maximise sample size and power while restricting variables included at each stage of the analysis. Variables significant at the $\mathrm{P}=0.1$ level in the univariable analysis, and with a prevalence among cases and controls of more than $2 \%$, were included in the initial multivariable models. We created three initial models by using a backward stepwise approach (that is, removal of non-significant $(\mathrm{P}>0.05)$ variables in a stepwise manner) of comorbidity (for the random control model, six variables reduced to four), historical symptoms (11 variables reduced to five), and physical examination variables (seven variables reduced to three). We then further reduced the resulting variables (12) by a backward stepwise approach in a final combined 
model. We used imputation to account for missing variables in the multivariable models. We included the continuous variables of heart rate and respiratory rate in the multivariable models as continuous variables by using cubic and quadratic terms, respectively, to maximise power, and according to the relation shown in modelling, by using generalised additive models at the univariable level. As both variables vary with age across the paediatric age spectrum, age was forced into the models using these variables. Oxygen saturations were dichotomised in the multivariable models to reflect clinical practice and biological plausibility.

We repeated the multivariable modelling in a sensitivity analysis without imputation and with heart rate and respiratory rate as dichotomised variables with clinically accepted thresholds, to assess the robustness of the imputation process and to generate more clinically meaningful odds ratios rather than odds ratios per change in unit from the modelling. We did further sensitivity analysis using bootstrap resampling techniques, with 1000 iterations, of the univariable analysis and of the multivariable models at all steps, to explore over-optimism of the variable selection processes used. We report effects for risk factors as adjusted odds ratios with $95 \%$ confidence intervals for dichotomised variables and as parameter estimates with $95 \%$ confidence intervals for continuous quadratic and cubic variables. We calculated the $\mathrm{C}$ statistics for all resulting models.

We did additional analyses of cases and the WILIE patients to compare emergency department management, subsequent management, and outcome among all patients with severe outcomes, regardless of influenza-like illness status, who either died or survived. We used SAS, version 9.1, software for all analyses.

\section{Results}

We identified 265 cases at 79 sites, as well as 56 additional children who fulfilled criteria for severe outcomes associated with $\mathrm{pH} 1 \mathrm{~N} 1$ but who did not have influenza-like illness at presentation (WILIE group). Boys constituted 151 (57\%) cases, with a similar proportion in the two control groups (table $1 \Downarrow$ ). The mean age of the cases was 6.6 (SD 4.7) years; the age matched controls were of a similar age, and the random controls were an average 14 months younger. Cases were more likely to look unwell at presentation, with PRISA-II scores suggesting a need for admission to intensive care (median 19, interquartile range 14-29). No significant differences existed between cases and controls in duration of symptoms of influenza-like illness or maximum temperature recorded at home. A history of cough was present in more than $90 \%$ of cases and controls. A history of a sore throat was more prevalent in both control groups compared with cases (table $1 \Downarrow$ ).

\section{Predictor variable data availability}

Data were available for each predictor variable in at least $90 \%$ of cases and controls. Exceptions included questions concerning whether the patient had seen a physician for the presenting illness (available for $86 \%$ of age matched controls), prolonged capillary refill time (available for $69-74 \%$ in all groups), and auscultatory findings and dehydration status (available for $89 \%$ and $81 \%$ of cases, respectively) (tables $2 \Downarrow$ and $3 \Downarrow$ ).

\section{Univariable analysis}

The results of the two univariable analyses comparing the cases with the random controls and the age matched controls were similar. We recorded 193 (73\%) cases with pre-existing comorbidities (comparison with random controls: odds ratio $4.2,95 \%$ confidence interval 2.8 to 6.4 ; comparison with age matched controls: $6.8,4.1$ to 11.1). Specifically, asthma, chronic lung disease, heart disease, preterm birth, and cerebral palsy/developmental delay were all significantly associated with case status. Furthermore, chronic renal disease $(n=8,3 \%)$ was present almost exclusively in cases. Diabetes, pregnancy, and immune suppression/malignancy occurred infrequently in both cases and controls (table $2 \Downarrow$ ).

At emergency department presentation, a history of dyspnoea, increased/purulent sputum, irritability, and wheezing were all significantly more common in cases than in controls, whereas diarrhoea, nausea/vomiting, generalised weakness,

syncope/dizziness, myalgia, and chest pain were not. A history of seizures $(n=28,11 \%)$ and apnoea $(n=10,4 \%)$ occurred almost exclusively in cases. Headache and rhinorrhoea occurred significantly less commonly in the cases compared with both control groups. Cases were also more likely to have been previously seen by a physician for the current illness and prescribed either antivirals (exclusively oseltamivir) or antibiotics (table $2 \Downarrow$ ). On physical examination in the emergency department, all signs investigated, except temperature above $38.9^{\circ} \mathrm{C}$, were associated with case status (table $3 \Downarrow$ ).

As expected, given the higher clinical severity,

laboratory/radiographic investigations within four hours of arrival in the emergency department were conducted more frequently in cases than in controls; $218(82 \%)$ of cases had chest radiography and $226(85 \%)$ had basic laboratory investigations. In comparison, only 74 (28\%) of random controls and $69(26 \%)$ of age matched controls had chest radiography, and $45(17 \%)$ of random controls and $44(17 \%)$ of age matched controls had basic laboratory investigations $(\mathrm{P}<0.001$ for all comparisons). In those who had laboratory and radiographic investigations within four hours of arrival in the emergency department, lobar pneumonias and platelet counts below 150 $000 / \mu \mathrm{L}$ were associated with case status, whereas non-lobar pneumonias, haemoglobin concentrations below $10 \mathrm{~g} / \mathrm{dL}$, leukocyte counts above $15000 / \mu \mathrm{L}$, neutrophil counts above 10 $000 / \mu \mathrm{L}$, blood urea nitrogen above $20 \mathrm{mg} / \mathrm{dL}$, and serum glucose above $200 \mathrm{mg} / \mathrm{dL}$ were not. Acidosis ( $\mathrm{pH}<7.3$ ) was exclusively present in cases, although blood $\mathrm{pH}$ was reported for only a few controls (table $3 \Downarrow$ ).

\section{Multivariable models}

We did not include variables from laboratory and radiographic investigations in the multivariable analysis owing to the low prevalence of these variables in the control groups. The multivariable analysis using the random and the age matched controls resulted in the same six variable model that included history of chronic lung disease, history of cerebral palsy/developmental delay, requirement for oxygen or low oxygen saturations, tachycardia relative to age, presence of chest retractions, and signs of dehydration $(\mathrm{C}$ statistic for model using random controls $0.925 ; \mathrm{C}$ statistic for model using age matched controls 0.905 ) (tables $2 \Downarrow$ and $3 \Downarrow$ ). Additionally, symptoms of breathlessness, irritability/drowsiness, and increased/purulent sputum were significant at the $\mathrm{P}<0.1$ level in the random control model, and symptoms of irritability/drowsiness were significant at the $\mathrm{P}<0.1$ level in the age matched control model (supplementary table A). In the bootstrap analysis, we identified the same possible predictor variables at all stages of the modelling process. Sensitivity analyses, without imputation and with heart rate and respiratory rate as dichotomised variables, using the random controls resulted in a seven variable model (removal of presence of dehydration and addition of symptoms 
of breathlessness and irritability/drowsiness), and those using the age matched controls resulted in a three variable model (removal of a history of chronic lung disease, tachycardia relative to age, and signs of dehydration) (supplementary table B).

\section{Outcome for cases and the WILIE group}

Of the 321 paediatric patients with severe $\mathrm{pH} 1 \mathrm{~N} 1$ outcome identified, 265 (83\%) fulfilled the Centers for Disease Control and Prevention criteria for influenza-like illness at emergency department presentation (cases). The additional 56 patients in the WILIE group had similar demographics and comorbidities to cases. However, more children in the WILIE group had immune suppression/malignancy $(\mathrm{n}=4,7 \%$; influenza-like illness cases $n=5,2 \%$; odds ratio $4.0,1.0$ to 5.4 ).

Within four hours of arrival at the emergency department, $63 \%$ of both cases and WILIE patients received antibiotic treatment, $40 \%$ received antiviral treatment, $64 \%$ received intravenous fluid boluses, $42 \%$ had ventilatory support started/continued, and $14 \%$ had inotropic support started. Two hundred and eighty six $(89 \%)$ patients were admitted to hospital at the time of their first emergency department presentation. Most admitted patients subsequently received antibiotic and antiviral treatment. Approximately one half of the children received systemic corticosteroid treatment, and a small number received immunoglobulin treatment. The most common complications during hospital admissions were secondary pneumonias, secondary bacteraemias, and acute respiratory distress syndrome (table $4 \Downarrow$ ).

\section{Mortality}

Among the 321 patients with severe pH1N1, 34 (11\%) deaths occurred $(27(10 \%)$ deaths among cases and 7 (13\%) among WILIE patients). Two patients arrived dead at the emergency department. The other 32 who subsequently died were less likely to have received antiviral treatment within the first four hours of initial emergency department presentation than were those who survived $(\mathrm{P}=0.02)$. Those who died received greater inotropic and ventilatory support and developed more frequent complications (table $5 \Downarrow$ ). Of the seven variables identified in the multivariable analyses, only cerebral palsy/developmental delay was associated with an increased risk of death (odds ratio 2.6, 1.2 to 5.5 ).

\section{Discussion}

We identified 321 children with severe outcomes due to $\mathrm{pH} 1 \mathrm{~N} 1$ infection at 79 sites in 12 countries, from a global consortium of paediatric emergency medicine networks during the first season of the H1N1 pandemic. Of these, $265(83 \%)$ presented to emergency departments with Centers for Disease Control and Prevention defined symptoms of influenza-like illness and were matched with random and age matched controls with influenza-like illness who did not have severe outcomes. We identified six factors that were associated with severe outcomes in children presenting to emergency departments with influenza-like illness, including two chronic disease factors (chronic lung disease and cerebral palsy/developmental delay) and four physiological/physical examination factors (requirement for oxygen or low oxygen saturations, tachycardia relative to age, presence of chest retractions, and signs of dehydration).

\section{Comparison with other studies}

In this large study, we compared comorbidities as well as clinical findings at presentation between children with and without severe outcomes who presented with influenza-like illness during a global pandemic. This analysis directly relates to the primary concern of the clinician who is caring for a child with an influenza-like illness in the middle of an epidemic: is this patient at risk of severe outcomes? One previous analysis detailed the risk of eight comorbidities in an aggregate dataset of 9700 children and adults with pH1N1 admitted to intensive care units in 19 countries. ${ }^{19}$ However, the study was limited by missing data, as only eight of the 19 countries provided full data on all eight risk factors. Furthermore, owing to lack of individual patient level data, meta-regression was not considered robust and the independent contribution of individual risk factors to outcome could not be determined. Risk was not provided for paediatric patients alone, and data were not provided on symptoms at presentation nor on physical examination or laboratory/radiographic findings. Nevertheless, the results support our finding of an increased risk of severe outcome among patients with one or more comorbidities, ${ }^{19}$ as do several smaller, single country paediatric studies. ${ }^{367910}$

Several smaller studies have described paediatric patients admitted to intensive care units by city (Denver, $n=80$ ) state (California, $n=96$ ), and country (Australia and New Zealand, $\mathrm{n}=83$; Argentina, $\mathrm{n}=147){ }^{3-15}$ However, these studies typically described demographic data and comorbidities and did not focus on clinical predictors of severity..$^{5-8}$ Intensive care unit cohorts from California and Denver were compared with $\mathrm{pH} 1 \mathrm{~N} 1$ hospital admissions to non-intensive care. Multivariable regression of the California data indicated that congenital heart disease and cerebral palsy/developmental delay were associated with severe outcome, whereas Hispanic ethnicity and black race were not. ${ }^{7}$ Similar analysis of the Denver data indicated that older age, pre-existing neurological conditions (including cerebral palsy/developmental delay), hypoxia on admission, and altered mental status were all associated with severe outcome. ${ }^{6}$ Cerebral palsy/developmental delay was significant in both of these previous cohorts, as it was in our random and age matched analyses. Such patients are considered to be at increased risk of respiratory infections owing to their inability to handle respiratory secretions as well as other factors, including under-nutrition. $^{26}$

Although all nine respiratory variables we report were found to be significantly associated with severe outcomes in our univariable analyses, chest retractions and hypoxia were the only respiratory variables present in both our random and age matched models. This suggests that these two respiratory variables are the strongest respiratory predictors of severe pH1N1 outcome. As diffuse alveolar damage, tracheitis, and necrotising bronchiolitis are consistent histopathological findings in fatal cases of $\mathrm{pH} 1 \mathrm{~N} 1,{ }^{1}$ that physical signs of dyspnoea and hypoxia are such important predictive factor is not surprising.

In our study, not surprisingly, laboratory and radiographic investigations were done more often in cases than in controls. The clinician's assessment of disease severity probably greatly affected this, with patients who looked most unwell incurring more investigations. Although these investigations were not included in the multivariable analyses, on univariable analysis these investigations, with the exception of chest radiography, seem to have limited predictive value for severe outcomes from $\mathrm{pH} 1 \mathrm{~N} 1$ infection for children presenting with influenza-like illness. 
A recent meta-analysis of the efficacy of oseltamivir in treating influenza infections emphasised the lack of data on its efficacy in preventing severe outcomes in $\mathrm{pH} 1 \mathrm{~N} 1$ infection and in influenza infections in general. ${ }^{27}$ In our study, we were able to show an association between oseltamivir treatment started in the emergency department and a reduced frequency of death in children subsequently admitted to an intensive care unit for assisted ventilation, inotropic/vasopressor support, or both. However, this result was confounded by the fact that patients who ultimately died presented to the emergency department later in the course of their illness than did those who survived, and perhaps it was this late presentation rather than the oseltamivir treatment itself that affected mortality. Overall, and consistent with other pH1N1 studies ${ }^{28-31}$ we confirmed that oseltamivir started within the first two days of symptoms is associated with decreased mortality. Although this evidence is not from randomised trials, it does support the timely use of oseltamivir in patients at risk of severe outcomes.

\section{Limitations and strengths of study}

Our study has several limitations owing to its retrospective design, including the risk of ascertainment, confirmation, and selection biases, as well as missing data. To minimise these limitations, senior physicians abstracted data at each site by following explicit instructions for data abstraction in a detailed manual of operations. In addition, data entry was facilitated by electronic forms with electronically configured logic checks. The use of two controls for each case limited both the risk of selection bias and the effect of missing data. The effect of missing data was further minimised by the use of imputation. The study was conducted predominately in academic centres, and this may raise concerns about generalisability to other settings. To overcome this, we excluded patients who were transferred from other emergency departments to our intensive care units, thus limiting cases and controls to "walk-ins" and referrals who were not already deemed critically ill.

Furthermore, we included cases from 79 emergency departments in 12 countries, with a wide range of number of annual paediatric visits (5000 to $>100000$ per year), in departments that are both paediatric emergency departments and mixed paediatric/adult emergency departments and are located in both secondary and tertiary hospitals.

Controls were included in the study irrespective of $\mathrm{pH} 1 \mathrm{~N} 1$ status and defined by influenza-like illness criteria alone. Therefore, control patients probably included patients with other viral infections as well as those with pH1N1 infection. The exact proportion of influenza-like illness presentations that tested positive for $\mathrm{pH} 1 \mathrm{~N} 1$ varied considerably between locations in the pandemic, although during the pandemic the prevalence of pH1N1 mirrored the prevalence of influenza-like illness. ${ }^{5}$ At any given site participating in this study, prevalence of $\mathrm{pH} 1 \mathrm{~N} 1$ among children presenting with influenza-like illness would have also varied temporally. However, the comparison of children with pH1N1 infections who had severe outcomes (cases) with influenza-like illness controls provides critical information to front line clinicians managing surges of children presenting with influenza-like illness during a pandemic. Recognition of children who will develop severe outcomes is difficult. A considerable proportion of paediatric presentations to emergency departments are with fever and tachycardia. In addition, febrile infants with influenza-like illness are often crying and inconsolable and are reported by their parents as being lethargic or irritable. Most children who present in this fashion have benign outcomes and disease course. ${ }^{32}$ Thus, our highly clinically relevant comparison is one of the key strengths of the study, as we have provided clinicians with meaningful information to differentiate those febrile children with influenza-like illness who are at greater risk of developing severe outcomes from those who are not. In contrast, studies comparing severe $\mathrm{pH} 1 \mathrm{~N} 1$ cases with non-severe $\mathrm{pH} 1 \mathrm{~N} 1$ controls have considerable selection bias and are of less clinical relevance, as rapid, inexpensive, reliable screening tests for $\mathrm{pH} 1 \mathrm{~N} 1$ are not available. The inclusion of patients with severe H1N1 without influenza-like illness in emergency departments (WILIE patients) in the study also provides reassurance that $83 \%$ of children destined to have severe $\mathrm{pH} 1 \mathrm{~N} 1$ present with symptoms of influenza-like illness.

Our final multivariable models included only predictors present in more than $2 \%$ of cases and controls to guarantee the robustness and stability of the final models. Parameter estimates for multivariable modelling are often not stable when presence of a variable occurs infrequently. Thus, some clinically important predictors may have been excluded from our models. For example, both history of apnoea and presenting already intubated occurred exclusively in $10(4 \%)$ cases. Similarly, history of renal disease (eight cases, $3 \%$ ), presentation after seizure ( 28 cases, $11 \%$ ), presence of prolonged capillary refill time or shock (51/183 cases, $28 \%)$, and presence of altered mental status (63/239 cases, $26 \%$ ) were almost exclusively present in cases. These variables remain potentially (and plausibly) important predictors of severe outcome and should not be overlooked by clinicians. We found very low prevalence of pregnancy, diabetes, and malignancy/immunosuppression among both cases and controls, so the findings of our study must be interpreted with caution in these patients.

The multivariable models for the random and age matched controls share the same six predictors, indicating the robustness and stability of both our selection and modelling processes. Symptoms of breathlessness, irritability/drowsiness, and increased/purulent sputum were significant at the $\mathrm{P}<0.1$ level in the modelling and should not be overlooked by clinicians. Five of the six predictors identified in the modelling process were also present in sensitivity analysis using non-imputed data and dichotomised respiration rate and heart rate variables, again supporting the final model. Signs of dehydration, the only predictor not present in the sensitivity models, was removed during the modelling process owing to lack of stability secondary to missing data and few controls with dehydration.

The study was not adequately powered to assess whether prognostic effects are consistent across sites and countries. This is likely, however, as all study sites were recognised emergency departments, all are part of established paediatric research networks, and predictor variables collected were all objective standard paediatric variables, supported by a priori standard international definitions.

Our study has several additional strengths. Our data are particularly robust owing to the precise definition of severe outcomes including ventilatory or inotropic support, in addition to death. This strict and objective outcome definition allows for increased confidence when comparing patients across centres; using intensive care unit admission alone as an outcome definition is subject to variability of thresholds for admission to intensive care between study sites. In other case series, ventilatory support of children with $\mathrm{pH} 1 \mathrm{~N} 1$ infection admitted to intensive care units has varied considerably from $30 \%$ to $100 \% .{ }^{83}$ Similarly, mortality has also varied substantially (7-39\%). ${ }^{5}$ However, those cohorts with higher mortality were more ill at intensive care unit admission, confirming that admission to intensive care units is subject to considerable variance and should not be used alone for global comparisons 
of disease severity. Our precise definition for severe outcomes also captured patients with a terminal comorbidity who may have been denied intensive care unit support, by including deaths irrespective of intensive care units admission. Furthermore, as intensive care unit, emergency department, laboratory, and mortality databases were searched for cases at sites, our search strategy would be unlikely to have missed a large number of cases. That our study found very similar case rates to regional reports provides further reassurance. ${ }^{5}$ Finally, although our study did not include any sites from low income countries where most childhood respiratory mortality occurs, our results are particularly generalisable to high income countries, as we included data from 79 sites in 12 countries in four of the six WHO regions.

\section{Conclusion}

Our study has identified robust, generalisable, and independent risk factors that may alert clinicians to children at risk of severe outcomes when presenting with influenza-like illness during a pandemic. Independent risk factors for severe outcomes included findings from premorbid history (chronic lung disease, cerebral palsy/developmental delay) and physiology/physical examination (requirement for oxygen, tachycardia relative to age, presence of chest retractions, signs of dehydration).

\section{Pediatric Emergency Research Networks (PERN) H1N1 working group:}

Research in European Paediatric Emergency Medicine (REPEM) site investigators: Patrick Van de Voorde, University Hospital, Ghent, Belgium; Yehezkel Waisman, Schneider Children's Medical Center of Israel, Petach Tikva, Israel; Itai Shavit and Yael Shachor, Meyer Children's Hospital, Rambam Medical Center, Haifa, Israel; Liviana Da Dalt, and Silvia Bressan, University of Padua and Padua Hospital, Padua, Italy; Paolo Valerio, Onze Lieve Vrouwe Gasthuis, Amsterdam, Netherlands; Merjin Bijlsma, Vrije Universiteit Medical Center, Amsterdam, Netherlands; Fleur de Lorijn, Academic Medical Center, Amsterdam, Netherlands; Cristina Camilo, and Ricardo M Fernandes, Hospital de Santa Maria, Lisbon, Portugal; Fernanda Rodrigues, Gustavo Januário, and Ana Brett Hospital Pediatrico, Coimbra, Portugal; Maria Joao Brito and Vera Rodrigues, Hospital de Dona Estefania, Lisbon, Portugal; Helena Carreiro and Pedro Nunes, Hospital Fernando Fonseca, Amadora, Portugal; Henrique Leitao and Hugo Cavaco, Hospital do Funchal, Funchal, Madeira, Portugal; Javier Benito and Santiago Mintegi, Hospital de Cruces, Bilbao, Spain; Ronan O'Sullivan and John Cronin, Our Lady's Children's Hospital Crumlin, Dublin, Ireland; Koert M Dolman, St Lucas Andreas Hospital, Amsterdam, Netherlands. Pediatric Emergency Care Applied Research Network (PECARN) site investigators (all from United States): Nathan Kuppermann and Leah Tzimenatos, University of California, Davis School of Medicine, Sacramento, CA; Marc H Gorelick and Lorin Browne, Medical College of Wisconsin and Children's Hospital of Wisconsin, Milwaukee, WI; Richard Ruddy, Cincinnati Children's Hospital Medical Center, Cincinnati, $\mathrm{OH}$; Rakesh Mistry and Richard Scarfone, Children's Hospital of Philadelphia, Philadelphia, PA; Kensuke Kanie and David Jaffe, St Louis Children's Hospital, St Louis, MO; Roni D Lane and Tellen Bennett, Primary Children's Medical Center, Salt Lake City, UT; James M Chamberlain, Children's National Medical Center, Washington DC; Richard Lichenstein, University of Maryland, Baltimore, MD; Aaron Chen and Jennifer Anders, Johns Hopkins University, Baltimore, MD; David Monroe, Howard County General Hospital, Columbia, MD; Lise E Nigrovic, Boston Children's Hospital, Boston, MA; Rachel Stanley, Alexander Rodgers, and Stuart Bradin, University of Michigan, Ann Arbor, Ml; Prashant Mahajan and Sara Ahmed, Children's Hospital of Michigan, Detroit, Ml; Dominic A Borgialli and Mahesh Sharman, Hurley Medical Center, Flint, MI; Bema Bonsu and Daniel M Cohen, Nationwide Children's Hospital, Columbus, $\mathrm{OH}$; Maria Kwok, Children's Hospital of
New York-Presbyterian, New York City, NY; Ellen Crain and Stephen M Blumberg, Jacobi Medical Center, Bronx, New York City, NY; Lalit Bajaj and Sara Deakyne, Children's Hospital Colorado, Denver, CO; Kathleen Lillis, Women and Children's Hospital of Buffalo, Buffalo, NY. Pediatric Emergency Medicine Collaborative Research Committee (PEM $\mathrm{CRC}$ ) site investigators (all from United States): Amanda Kasem, Phoenix Children's Hospital, Phoenix, AZ; Jeff Blake, Mary Bridge Children's Hospital, Tacoma, WA; Jennifer Chao, King's County Hospital, Brooklyn, New York City, NY; William Krief, Cohen Children's Medical Center, New York City, NY; Christopher Pruitt, University of Alabama, Birmingham, AL; John T Kanegaye and Paul Ishimine, Rady Children's Hospital San Diego, CA; Ethan S Wiener, Goryeb Children's Hospital, Morristown, NJ; Harold K Simon and Brian E Costello, Emory University School of Medicine, Children's Healthcare of Atlanta, Atlanta, GA; Brian Bates, Methodist Children's Hospital, San Antonio, TX; Marissa Hendrickson, University of Minnesota Amplatz Children's Hospital, Minneapolis, MN; Scott G Weiner, Tufts Medical Center, Boston, MA; Charles G Macias, Texas Children's Hospital, Houston, TX; Jose Ramirez and Kelly Cramm, Arnold Palmer Hospital for Children, Orlando, FL; Laleh Bahar-Posey and Stacey Keller, All Children's Hospital, St Petersburg, FL; Christine Cho and Carina Baird, Children's Hospital and Research Center Oakland, Oakland, CA; Micheyle Goldman, Joe Di Maggio Children's Hospital, Hollywood, FL; Eugene Izsak, Toledo Children's Hospital, Toledo, OH; Thomas Abramo, Vanderbilt University Medical Center, Nashville, TN; Muhammad Waseem, Lincoln Medical and Mental Health Center, Bronx, NY.

Pediatric Emergency Research Canada (PERC) site investigators (all from Canada): Quynh Doan and Kiarash Mousavinejad, British Columbia Children's Hospital, Vancouver, BC; Graham Thompson, Alberta Children's Hospital, Calgary, AB; Bruce Wright, Stollery Children's Hospital, Edmonton, AB; Lynne Warda, Children's Hospital of Winnipeg, MB; Naveen Poonai, Children's Hospital of Western Ontario, London, ON; Suzanne Schuh, Hospital for Sick Children, Toronto, ON; Gina Neto, Children's Hospital of Eastern Ontario, Ottawa, ON; Richard Van Wylick, Kingston General Hospital and Queen's University, Kingston, ON; Chantal Guimont and Emilio Aquirre, Centre hospitalier de I'Université Laval, Quebec City, QC; Karen J L Black, IWK Health Center, Halifax, NS; Robert Porter, Janeway Children's Hospital, St John's, NF; Philippe Jouvet and Gwënaelle Bidet, CHU St Justine Hospital, Montréal, QC.

Paediatric Research in Emergency Departments International Collaborative (PREDICT) site investigators: Jacquie Schutz, Women's and Children's Hospital, Adelaide, SA, Australia; David Herd, Mater Children's Hospital, Brisbane, Qld, Australia; Louisa Wilson, Sydney Children's Hospital, Randwick, NSW, Australia; Mark Lyttle and Franz Babl, Royal Children's Hospital, Melbourne, Vic, Australia; Meredith Borland, Princess Margaret Hospital for Children, Perth, WA, Australia; Jason Acworth, Royal Children's Hospital, Brisbane, Qld, Australia; Nicholas Cheng, The Children's Hospital at Westmead, Sydney, NSW, Australia; David Krieser, Sunshine Hospital, Melbourne, Vic, Australia; Stuart Dalziel and Olwen Gilbert, Starship Children's Hospital, Auckland, New Zealand; Edward Oakley, Monash Medical Center, Melbourne, Vic, Australia; Jocelyn Neutze, Kidz First Hospital, Middlemore, Auckland, New Zealand; Mark Lee, John Hunter Hospital, Newcastle, NSW, Australia; Christa Bell, Gold Coast Hospital, Qld, Australia; Gene Ong, KK Women's and Children's Hospital, Singapore.

We also thank Long Ma and Victor M Gonzalez, Baylor College of Medicine, Houston, TX, USA, for their expertise in data management and the ANZIC influenza (INFINITE) investigators and the ANZPIC Registry of the Austrian and New Zealand Intensive Care Society Paediatric Study Group, Melbourne, Vic, Australia, for access to their data. We thank Tom Beattie, Royal Hospital for Sick Children, Edinburgh, UK, for his involvement in establishing PERN and helping to conceive and design the study. 


\section{What is already known on this topic}

During the $2009 \mathrm{H} 1 \mathrm{~N} 1$ pandemic, paediatric emergency departments worldwide experienced a surge in total volume of patients owing to children presenting with influenza-like illness

Risk factors for subsequent severe outcome in such children were not known

\section{What this study adds}

This global study identified six independent risk factors for severe outcomes in children presenting with influenza-like illness during the 2009 H1N1 pandemic

These factors were history of chronic lung disease and cerebral palsy/developmental delay, signs of chest retractions, tachycardia for age, requirement for oxygen, and signs of dehydration

These risk factors may alert clinicians to children at risk of severe outcomes when presenting with influenza-like illness during future pandemics

Contributors: All authors conceived and designed the study. SRD, CGM, RMF, NK, DWJ, YW, NC, JA, JMC, MHO, PV, and KJLB acquired the data. SRD and JMDT analysed the data. All authors interpreted the data. SRD drafted the article. All authors revised the article and give final approval for publication. SRD is the guarantor.

Funding: PECARN is supported by HRSA/MCHB/EMSC through the following cooperative agreements: U03MC00001, U03MC00003, U03MC00006, U03MC00007, U03MC00008, U03MC22684, and U03MC22685. SRD is supported by the Health Research Council of New Zealand. JMDT received funding from the Logan Campbell Trust, Auckland, New Zealand, to attend an investigator meeting with time funded by CureKids, New Zealand. Investigators' time was funded by their host institutions. No funding bodies had any role in study design, data collection and analysis, decision to publish, or preparation of the manuscript.

Competing interests: All authors have completed the ICMJE uniform disclosure form at www.icmje.org/coi_disclosure.pdf (available on request from the corresponding author) and declare: no support from any organisation for the submitted work; no financial relationships with any organisations that might have an interest in the submitted work in the previous three years; no other relationships or activities that could appear to have influenced the submitted work.

Ethical approval: This study was approved by the local institutional review boards/ethics committees at all sites.

Data sharing: No additional data available.

1 WHO Consultation on Clinical Aspects of Pandemic (H1N1) 2009 Influenza. Clinical aspects of pandemic 2009 influenza A (H1N1) virus infection. N Engl J Med 2010;362:1708-19

2 Centers for Disease Control and Prevention. Surveillance for pediatric deaths associated with 2009 pandemic influenza A (H1N1) virus infection—United States, April-August 2009. MMWR Morb Mortal Wkly Rep 2009;58:941-7.

3 Libster R, Coviello S, Cavalieri ML, Morosi A, Alabart N, Alvarez L, et al. Pediatric hospitalizations due to influenza in 2010 in Argentina. N Engl J Med 2010;363:2472-3.

4 Fanella ST, Pinto MA, Bridger NA, Bullard JM, Coombs JM, Crockett ME, et al. Pandemic (H1N1) 2009 influenza in hospitalized children in Manitoba: nosocomial transmission and lessons learned from the first wave. Infect Control Hosp Epidemiol 2011;32:435-43.

5 Yung M, Slater A, Festa M, Williams G, Erickson S, Pettila V, et al. Pandemic H1N1 in children requiring intensive care in Australia and New Zealand during winter 2009. Pediatrics 2011;127:e156-63.

6 Bagdure D, Curtis DJ, Dobyns E, Glode MP, Dominguez SR. Hospitalized children with 2009 pandemic influenza A (H1 N1): comparison to seasonal influenza and risk factors for admission to the ICU. PLOS ONE 2010;5:e15173.

7 Louie JK, Gavali S, Acosta M, Samuel MC, Winter K, Jean C, et al. Children hospitalized with 2009 novel influenza A(H1N1) in California. Arch Pediatr Adolesc Med 2010;164:1023-31.

8 Farias JA, Fernandez A, Monteverde E, Vidal N, Arias P, Montes MJ, et al. Critically ill infants and children with influenza $A(H 1 N 1)$ in pediatric intensive care units in Argentina. Intensive Care Med 2010;36:1015-22.

9 O'Riordan S, Barton M, Yau Y, Read SE, Allen U, Tran D. Risk factors and outcomes among children admitted to hospital with pandemic H1N1 influenza. CMAJ 2010;182:39-44.

10 Kumar S, Havens PL, Chusid MJ, Willoughby REJ, Simpson P, Henrickson KJ. Clinical and epidemiologic characteristics of children hospitalized with 2009 pandemic $\mathrm{H} 1 \mathrm{~N} 1$ influenza A infection. Pediatr Infect Dis J 2010;29:591-4.

11 Launay E, Ovetchkine P, Saint-Jean M, Coic L, Ducruet T, Charest H, et al. Novel influenza A (H1N1): clinical features of pediatric hospitalizations in two successive waves. Int J Infect Dis 2011:15:e122-30.

12 Stein M, Tasher D, Glikman D, Shachor-Meyouhas Y, Barkai G, Yochai AB, et al. Hospitalization of children with influenza A(H1N1) virus in Israel during the 2009 outbreak in Israel: a multicenter survey. Arch Pediatr Adolesc Med 2010;164:1015-22.
13 Calitri C, Gabiano C, Garazzino S, Pinon M, Zoppo M, Cuozzo M, et al. Clinical features of hospitalised children with $2009 \mathrm{H} 1 \mathrm{~N} 1$ influenza virus infection. Eur J Pediatr 2010;169:1511-5.

14 Herberg JA, Jones KD, Paulus S, Gormley S, Muir D, Cooper M, et al. Comparison of pandemic and seasonal influenza reveals higher mortality and increased prevalence of shock in children with severe h1n1/09 infection. Pediatr Infect Dis J 2011:30:438-40.

15 Lister P, Reynolds F, Parslow R, Chan A, Cooper M, Plunkett A, et al. Swine-origin influenza virus $\mathrm{H} 1 \mathrm{~N} 1$, seasonal influenza virus, and critical illness in children. Lancet 2009;374:605-7.

16 Louie JK, Acosta M, Winter K, Jean C, Gavali S, Schechter R, et al. Factors associated with death or hospitalization due to pandemic 2009 influenza $A(\mathrm{H} 1 \mathrm{~N} 1)$ infection in California. JAMA 2009:302:1896-902.

17 Jain S, Kamimoto L, Bramley AM, Schmitz AM, Benoit SR, Louie J, et al. Hospitalized patients with 2009 H1N1 influenza in the United States, April-June 2009. N Engl J Med 2009;361:1935-44

18 Campbell A, Rodin R, Kropp R, Mao Y, Hong Z, Vachon J, et al. Risk of severe outcomes among patients admitted to hospital with pandemic (H1N1) influenza. CMAJ 2010;182:349-55

19 Van Kerkhove MD, Vandemaele KAH, Shinde V, Jaramillo-Gutierrez G, Koukounari A, Donnelly CA, et al. Risk factors for severe outcomes following 2009 influenza A (H1N1) infection: a global pooled analysis. PLoS Med 2011;8:e1001053.

20 Chowell G, Echevarria-Zuno S, Viboud C, Simonsen L, Tamerius J, Miller MA, et al. Characterizing the epidemiology of the 2009 influenza A/H1N1 pandemic in Mexico. PLoS Med 2011:8:e1000436.

21 Bryant PA, Tebruegge M, Papadakis G, Clarke C, Barnett P, Daley AJ, et al. Clinical and microbiologic features associated with novel swine-origin influenza A pandemic 2009 (H1N1) virus in children: a prospective cohort study. Pediatr Infect Dis J 2010;29:694-8.

22 Jhung MA, Swerdlow D, Olsen SJ, Jernigan D, Biggerstaff M, Kamimoto L, et al. Epidemiology of 2009 pandemic influenza A (H1N1) in the United States. Clin Infect Dis 2011;52(suppl 1):S13-26.

23 Klassen TP, Acworth J, Bialy L, Black K, Chamberlain JM, Cheng N, et al. Pediatric emergency research networks: a global initiative in pediatric emergency medicine. Pediatr Emerg Care 2010;26:541-3.

24 Gilbert EH, Lowenstein SR, Koziol-McLain J, Barta DC, Steiner J. Chart reviews in emergency medicine research: where are the methods? Ann Emerg Med 1996;27:305-8.

25 Chamberlain JM, Patel KM, Pollack MM. The pediatric risk of hospital admission score: a second-generation severity-of-illness score for pediatric emergency patients. Pediatrics 2005;115:388-95

26 Sullivan PB, Lambert B, Rose M, Ford-Adams M, Johnson A, Griffiths P. Prevalence and severity of feeding and nutritional problems in children with neurological impairment: Oxford Feeding Study. Dev Med Child Neurol 2000;42:674-80.

27 Shun-Shin M, Thompson M, Heneghan C, Perera R, Harnden A, Mant D. Neuraminidase inhibitors for treatment and prophylaxis of influenza in children: systematic review and meta-analysis of randomised controlled trials. BMJ 2009;339:b3172.

28 Fuhrman C, Bonmarin I, Bitar D, Cardoso T, Duport N, Herida M, et al. Adult intensive-care patients with 2009 pandemic influenza $\mathrm{A}(\mathrm{H} 1 \mathrm{~N} 1)$ infection. Epidemiol Infect 2011;139:1202-9

29 Hiba V, Chowers M, Levi-Vinograd I, Rubinovitch B, Leibovici L, Paul M. Benefit of early treatment with oseltamivir in hospitalized patients with documented 2009 influenza A (H1N1): retrospective cohort study. J Antimicrob Chemother 2011;66:1150-5.

30 Lockman JL, Fischer WA, Perl TM, Valsamakis A, Nichols DG. The critically ill child with novel H1N1 influenza A: a case series. Pediatr Crit Care Med 2010;11:173-8.

31 Lee N, Chan PK, Lui GC, Wong BC, Sin WW, Choi KW, et al. Complications and outcomes of pandemic 2009 influenza A (H1N1) virus infection in hospitalized adults: how do they differ from those in seasonal influenza? $J$ Infect Dis 2011;203:1739-47.

32 Brierley J, Carcillo JA, Choong K, Cornell T, DeCaen A, Deymann A, et al. Clinical practice parameters for hemodynamic support of pediatric and neonatal septic shock: 2007 update from the American College of Critical Care Medicine. Crit Care Med 2009;37:666-88.

33 Ostovar GA, Rubin LG, Rajan S, Sood SK, Kohn N. Comparison of the clinical features of children hospitalized with pandemic 2009 A:H1N1 and seasonal influenza. Clin Pediatr 2011;50:348-54.

Accepted: 22 July 2013

\section{Cite this as: BMJ 2013;347:f4836}

This is an Open Access article distributed in accordance with the Creative Commons Attribution Non Commercial (CC BY-NC 3.0) license, which permits others to distribute, remix, adapt, build upon this work non-commercially, and license their derivative works on different terms, provided the original work is properly cited and the use is non-commercial. See: http://creativecommons.org/licenses/by-nc/3.0/. 


\section{Tables}

Table 1| Age, severity at emergency department presentation, and Centers for Disease Control and Prevention influenza-like illness characteristics of children in all study groups. Values are numbers (percentages) unless stated otherwise

Characteristics

Cases $(n=265)$ Random controls $(n=265)$ Age matched controls $(n=265)$

Mean (SD) age (years)

$6.6(4.7) \quad 5.4(4.2)^{*} \quad 6.4(4.5)$

Male sex

$151(57)$

$143(54)$

Median (interquartile range) PRISA-II score

$19(14-29)$

$137(52)$

$5(0-5)^{\star}$

Mean (SD) maximum fever recorded at home $\left({ }^{\circ} \mathrm{C}\right)$

$39.0(0.7)$

$5(3-6)^{*}$
$39.0(0.8)$

Median (interquartile range) fever duration (days)

$2(1-3)$

$39.2(0.8)$
$2(1-3)$

Cough on history $259(98)$

$2(1-3)$
$245(93)^{*}$

Median (interquartile range) cough duration (days) $2(1-3)$ $255(96)$ $2(1-3)$

Sore throat on history $46(17)$ $2(1-3)$ $88(33)^{*}$

Median (interquartile range) sore throat duration (days)

$2(1-3)$ $2(1-3)$

PRISA-II=Pediatric Risk of Admission Score (second generation). ${ }^{25}$

${ }^{*} \mathrm{P}<0.05$ compared with cases. 
Table 2| Comparison of factors from comorbidities and history of current illness associated with development of severe outcomes from pH1N1 infection between cases and control study groups

\begin{tabular}{|c|c|c|c|c|c|c|c|}
\hline \multirow[b]{3}{*}{ Predictor } & \multirow{3}{*}{$\begin{array}{c}\text { Cases } \\
(n=265)-N o \\
(\%)\end{array}$} & \multicolumn{3}{|c|}{ Random controls $(n=265)$} & \multicolumn{3}{|c|}{ Age matched controls $(n=265)$} \\
\hline & & \multirow[b]{2}{*}{ No (\%) } & \multicolumn{2}{|c|}{ Odds ratio $(95 \% \mathrm{Cl})^{\star}$} & \multirow[b]{2}{*}{ No (\%) } & \multicolumn{2}{|c|}{ Odds ratio $(95 \% \mathrm{Cl})^{*}$} \\
\hline & & & $\begin{array}{l}\text { Univariable } \\
\text { analysis }\end{array}$ & $\begin{array}{l}\text { Multivariable } \\
\text { model }\end{array}$ & & Univariable analysis & $\begin{array}{l}\text { Multivariable } \\
\text { model }\end{array}$ \\
\hline Male sex & $151(57)$ & $137(52)$ & $1.2(0.9$ to 1.7$)$ & $\dagger$ & $143(54)$ & $1.1(0.8$ to 1.6$)$ & $\dagger$ \\
\hline \multicolumn{8}{|l|}{ Comorbidities } \\
\hline Asthma & $94(36)$ & $66(25)$ & 1.7 (1.1 to 2.5$)$ & $\ddagger$ & $48(18)$ & 2.7 (1.7 to 4.2$)$ & $\ddagger$ \\
\hline Pregnancy & $1(0)$ & $0(0)$ & $\S$ & 凤 & $0(0)$ & $\S$ & ๆ \\
\hline Chronic lung disease & $50(19)$ & $4(2)$ & 14.5 (5.3 to 39.9$)$ & $\begin{array}{c}10.3(1.5 \text { to } \\
69.8)\end{array}$ & $7(3)$ & 9.8 (4.2 to 22.8$)$ & $\begin{array}{c}8.5(1.6 \text { to } \\
45.1)\end{array}$ \\
\hline Heart disease & $30(11)$ & $9(3)$ & $3.3(1.6$ to 7.0$)$ & $\dagger$ & $5(2)$ & $6.0(2.3$ to 15.5$)$ & $\ddagger$ \\
\hline Diabetes & $3(1)$ & $0(0)$ & $\S$ & I & $2(1)$ & $1.5(0.3$ to 9.0$)$ & গ \\
\hline Renal disease & $8(3)$ & $0(0)$ & $\S$ & I & $1(0)$ & $8.0(1.0$ to 64.0$)$ & গ \\
\hline Malignancy/immunosuppression & $5(2)$ & $3(1)$ & $1.7(0.4$ to 7.0$)$ & গ & $4(2)$ & $1.3(0.3$ to 4.7$)$ & I \\
\hline $\begin{array}{l}\text { Cerebral palsy/developmental } \\
\text { delay }\end{array}$ & $72(27)$ & $7(3)$ & 14.0 (5.7 to 34.7$)$ & $\begin{array}{c}10.2(2.0 \text { to } \\
51.4)\end{array}$ & $5(2)$ & 34.5 (8.5 to 141$)$ & $\begin{array}{l}65.9(8.6 \text { to } \\
506)\end{array}$ \\
\hline Preterm birth & $42(16)$ & $14(5)$ & 3.5 (1.8 to 6.9$)$ & $\dagger$ & $14(5)$ & 4.1 (2.0 to 8.5$)$ & $\dagger$ \\
\hline \multicolumn{8}{|l|}{ Current illness } \\
\hline Dyspnoea & $155(58)$ & $35(13)$ & $11.0(6.1$ to 19.9$)$ & $\ddagger$ & $31(12)$ & $9.9(5.7$ to 17.1$)$ & $\ddagger$ \\
\hline Apnoea & $10(4)$ & $0(0)$ & $\S$ & I & $0(0)$ & $\S$ & গ \\
\hline Headache & $19(7)$ & $40(15)$ & $0.4(0.2$ to 0.7$)$ & $\dagger$ & $46(17)$ & $0.3(0.2$ to 0.6$)$ & $t$ \\
\hline Nausea/vomiting & $98(37)$ & $89(34)$ & 1.2 (0.8 to 1.7$)$ & $\dagger$ & $86(33)$ & $1.2(0.9$ to 1.7$)$ & $\dagger$ \\
\hline Diarrhoea & $35(13)$ & $27(10)$ & 1.3 (0.8 to 2.3$)$ & $\dagger$ & $35(13)$ & $1.0(0.6$ to 1.6$)$ & $\dagger$ \\
\hline Increased/purulent sputum & $35(13)$ & $4(2)$ & 11.3 (3.5 to 36.9 ) & $\ddagger$ & $5(2)$ & 11.0 (3.4 to 35.9 ) & $\ddagger$ \\
\hline Seizures & $28(11)$ & $1(0)$ & 28.0 (3.8 to 206 ) & ๆ & $5(2)$ & $5.6(2.2$ to 14.5$)$ & $t$ \\
\hline Generalised weakness & $27(10)$ & $16(6)$ & 2.3 (1.0 to 5.9$)$ & $\ddagger$ & $18(7)$ & $1.6(0.8$ to 3.1$)$ & $t$ \\
\hline Dizziness & $5(2)$ & $5(2)$ & 1.0 (0.3 to 4.0$)$ & $\dagger$ & $9(3)$ & $0.6(0.2$ to 1.7$)$ & $\dagger$ \\
\hline Irritable/drowsy & $55(21)$ & $24(9)$ & 2.6 (1.6 to 4.5$)$ & $\ddagger$ & $22(8)$ & $2.9(1.7$ to 5.1$)$ & $\ddagger$ \\
\hline Collapse/syncope/dizziness & $2(1)$ & $0(0)$ & $\S$ & I & $3(1)$ & 0.7 (0.1 to 4.0$)$ & ף \\
\hline Wheezing & $69(26)$ & $31(12)$ & $2.8(1.7$ to 4.6$)$ & $\dagger$ & $15(6)$ & $7.0(3.5$ to 14.1$)$ & $t$ \\
\hline Myalgia & $18(7)$ & $38(14)$ & 0.4 (0.2 to 0.8$)$ & $t$ & $27(10)$ & 0.6 (0.3 to 1.2$)$ & $t$ \\
\hline Chest pain & $18(7)$ & $13(5)$ & $1.4(0.7$ to 2.8$)$ & $\dagger$ & $9(3)$ & $2.3(0.9$ to 5.6$)$ & $t$ \\
\hline Rhinorrhoea & $87(33)$ & $130(49)$ & 0.4 (0.3 to 0.7$)$ & $\ddagger$ & $126(48)$ & 0.5 (0.3 to 0.7$)$ & $\ddagger$ \\
\hline Previously seen physician & $134 / 251(53)$ & $79 / 240(33)$ & 2.5 (1.7 to 3.9$)$ & $\dagger$ & $81 / 227(36)$ & $2.2(1.4$ to 3.2$)$ & $t$ \\
\hline Antiviral treatment started & 23/254 (9) & $11 / 254(4)$ & $2.3(1.1$ to 5.1$)$ & $\dagger$ & $8 / 260(3)$ & $2.9(1.3$ to 6.4$)$ & $t$ \\
\hline Antibiotics started & $66 / 250(26)$ & $35 / 249(14)$ & 2.1 (1.3 to 3.4 ) & $\dagger$ & $34 / 256(13)$ & $2.2(1.4$ to 3.6$)$ & $t$ \\
\hline
\end{tabular}

*Random control results adjusted for site, and age matched control results adjusted for site and age, using conditional logistic regression. †Not identified as significant in univariable analyses or in initial multivariable models.

$\ddagger$ Not identified as significant in final model.

§Estimate and $\mathrm{Cl}$ not calculated owing to non-prevalence in controls.

INot included in modelling process owing to prevalence in cases or controls $\leq 2 \%$. 
Table 3| Comparison of factors from physical examination and laboratory and radiographic investigations, associated with development of severe outcomes from pH1N1 infection between cases and control study groups

\begin{tabular}{|c|c|c|c|c|c|c|c|}
\hline \multirow[b]{3}{*}{ Predictor } & \multirow{3}{*}{$\begin{array}{c}\text { Cases } \\
(n=265)-N o \\
(\%)\end{array}$} & \multicolumn{3}{|c|}{ Random controls $(n=265)$} & \multicolumn{3}{|c|}{ Age matched controls $(n=265)$} \\
\hline & & \multirow[b]{2}{*}{ No (\%) } & \multicolumn{2}{|c|}{ Odds ratio $(95 \% \mathrm{Cl})^{*}$} & \multirow[b]{2}{*}{ No (\%) } & \multicolumn{2}{|c|}{ Odds ratio $(95 \% \mathrm{Cl})^{*}$} \\
\hline & & & $\begin{array}{l}\text { Univariable } \\
\text { analysis }\end{array}$ & $\begin{array}{l}\text { Multivariable } \\
\text { model }\end{array}$ & & $\begin{array}{l}\text { Univariable } \\
\text { analysis }\end{array}$ & $\begin{array}{c}\text { Multivariable } \\
\text { model }\end{array}$ \\
\hline \multicolumn{8}{|l|}{ Physical examination } \\
\hline Intubated on arrival & $10 / 261(4)$ & $0 / 261(0)$ & $\S$ & ๆ & $0(0)$ & $\S$ & I \\
\hline Fever $>38.9^{\circ} \mathrm{C}$ & $62(23)$ & $66(25)$ & 0.9 (0.6 to 1.4$)$ & $\dagger$ & $73(28)$ & 0.8 (0.5 to 1.2$)$ & $\dagger$ \\
\hline $\begin{array}{l}\text { Respiratory rate* } \\
\text { (linear) }\end{array}$ & - & - & $\begin{array}{c}0.11(-0.0036 \text { to } \\
0.22)\end{array}$ & $\dagger$ & - & $0.15(0.046$ to 0.26$)$ & $\dagger$ \\
\hline $\begin{array}{l}\text { Respiratory rate* } \\
\text { (quadratic) }\end{array}$ & - & - & $\begin{array}{c}-0.00026(-0.0017 \\
\text { to } 0.0011)\end{array}$ & $\dagger$ & - & $\begin{array}{c}-0.00057(-0.0019 \\
\text { to } 0.00079)\end{array}$ & $\dagger$ \\
\hline Heart rate* $^{*}$ linear) $)^{\star *}$ & - & - & $\begin{array}{c}-0.35(-0.72 \text { to } \\
0.028)\end{array}$ & $\begin{array}{c}0.72(0.0074 \text { to } \\
1.44)\end{array}$ & - & $\begin{array}{c}-0.19(-0.30 \text { to } \\
-0.086)\end{array}$ & $\begin{array}{c}-0.085(-0.16 \\
\text { to }-0.0079)\end{array}$ \\
\hline $\begin{array}{l}\text { Heart rate* } \\
\text { (quadratic) }^{* \star}\end{array}$ & - & - & $\begin{array}{c}0.0029(0.00017 \text { to } \\
0.0055)\end{array}$ & $\begin{array}{l}-0.0055 \\
(-0.011 \text { to } \\
-0.0003)\end{array}$ & - & $\begin{array}{c}0.0019(0.00093 \text { to } \\
0.0029)\end{array}$ & $\begin{array}{c}0.00041 \\
(0.00009 \text { to } \\
0.00072) \\
\end{array}$ \\
\hline Heart rate $^{\star}(\text { cubic })^{\star *}$ & - & - & $\begin{array}{l}-0.000007 \\
(-0.000013 \text { to } \\
-0.0000008)\end{array}$ & $\begin{array}{c}0.000013 \\
(0.0000006 \text { to } \\
0.000025)\end{array}$ & - & $\begin{array}{l}-0.000005 \\
(-0.000007 \text { to } \\
-0.000002)\end{array}$ & - \\
\hline $\begin{array}{l}\text { On oxygen or } \\
\text { saturation }<93 \%\end{array}$ & $151 / 247(61)$ & $13 / 220(6)$ & $19.8(8.7$ to 45.0$)$ & $\begin{array}{c}5.8(2.0 \text { to } \\
16.2)\end{array}$ & $16 / 216(7)$ & 39.7 (12.6 to 125$)$ & $\begin{array}{c}12.9 \text { (3.8 to } \\
44.2)\end{array}$ \\
\hline Chest retractions & $149 / 240(62)$ & $22 / 250(9)$ & 20.1 (9.6 to 42.3$)$ & $\begin{array}{c}9.6(3.2 \text { to } \\
29.0)\end{array}$ & $20 / 248(8)$ & 18.5 (9.0 to 38.0$)$ & $\begin{array}{c}12.9(4.2 \text { to } \\
38.9)\end{array}$ \\
\hline $\begin{array}{l}\text { Accessory muscle } \\
\text { use }\end{array}$ & 120/222 (54) & $15 / 244(6)$ & $17.2(8.2$ to 36.1$)$ & $\dagger$ & $11 / 241(5)$ & $25.2(10.7$ to 59.7$)$ & $\ddagger$ \\
\hline Crepitations/rales & $85 / 236(36)$ & $24 / 252(10)$ & 7.2 (3.8 to 13.5$)$ & $\dagger$ & $18 / 250(7)$ & $7.8(4.1$ to 14.8$)$ & $\dagger$ \\
\hline Wheeze/rhonchi & $120 / 248(48)$ & $31 / 259(12)$ & 7.6 (4.4 to 13.2$)$ & $\dagger$ & 28/254 (11) & $8.1(4.6$ to 14.4$)$ & $\dagger$ \\
\hline $\begin{array}{l}\text { Prolonged } \\
\text { CRT/shocked }\end{array}$ & $51 / 183(28)$ & $3 / 189(2)$ & $25.0(6.1$ to 103$)$ & ๆ & 4/196 (2) & 16.7 (5.2 to 53.4$)$ & I \\
\hline Altered mental status & $63 / 239(26)$ & $2 / 255(1)$ & 77.8 (10.5 to 578$)$ & ๆ & $2 / 254(1)$ & $76.3(10.3$ to 564$)$ & ๆ \\
\hline Signs of dehydration & $43 / 214(20)$ & 5/244 (2) & 14.3 (4.9 to 42.1$)$ & $\begin{array}{c}8.8(1.6 \text { to } \\
49.3)\end{array}$ & 7/246 (3) & 12.3 (4.5 to 33.6 ) & $\begin{array}{c}10.7(2.0 \text { to } \\
57.8)\end{array}$ \\
\hline \multicolumn{8}{|c|}{ Laboratory and radiographic investigations } \\
\hline $\begin{array}{l}\text { Abnormal chest } \\
\text { radiograph }\end{array}$ & $118 / 218(54)$ & $14 / 74(19)$ & $5.1(2.7$ to 9.6$)$ & †† & $11 / 69(16)$ & 6.2 (3.1 to 12.5$)$ & †† \\
\hline Lobar pneumonia & $100 / 211(47)$ & $13 / 73(18)$ & $5.0(1.7$ to 14.6$)$ & t† & $10 / 67(15)$ & $6.0(1.8$ to 20.4$)$ & †† \\
\hline Bronchopneumonia & 29/195 (15) & $6 / 69(9)$ & $1.7(0.4$ to 7.0$)$ & †† & 2/67 (3) & $5.7(1.3$ to 24.5$)$ & t† \\
\hline $\begin{array}{l}\text { Haemoglobin }<10 \\
\text { g/dL }\end{array}$ & 24/203 (12) & $4 / 40(10)$ & 1.2 (0.4 to 3.7$)$ & †† & $4 / 39(10)$ & 1.2 (0.4 to 3.6$)$ & †† \\
\hline $\begin{array}{l}\text { Total leukocyte count } \\
>15000 / \mu \mathrm{L}\end{array}$ & $38 / 206(18)$ & $12 / 42(29)$ & $0.6(0.3$ to 1.2$)$ & t† & $4 / 40(10)$ & $2.0(0.7$ to 6.1$)$ & †† \\
\hline $\begin{array}{l}\text { Neutrophil count }>10 \\
000 / \mu \mathrm{L}\end{array}$ & 70/197 (36) & $9 / 41(22)$ & $2.0(0.9$ to 4.3$)$ & t† & $11 / 32(34)$ & $1.2(0.5$ to 2.5$)$ & †† \\
\hline $\mathrm{pH}<7.3$ & 47/147 (32) & $0 / 3(0)$ & $\S$ & t† & $0 / 6(0)$ & $\S$ & †† \\
\hline $\begin{array}{l}\text { Bicarbonate }<21 \\
\mathrm{mmol} / \mathrm{L}\end{array}$ & 65/188 (35) & 7/22 (32) & 1.1 (0.4 to 2.9 ) & †† & 8/22 (36) & 0.9 (0.4 to 2.3) & †† \\
\hline Urea >20 mg/dL & 37/191 (19) & $0 / 28(0)$ & $\S$ & t† & $4 / 29(14)$ & $1.5(0.5$ to 4.6$)$ & †† \\
\hline Glucose $>200 \mathrm{mg} / \mathrm{dL}$ & 24/187 (13) & $1 / 24(4)$ & $3.4(0.4$ to 26.2$)$ & t† & $3 / 26(12)$ & $1.1(0.3$ to 4.0$)$ & t† \\
\hline \multicolumn{8}{|l|}{ Platelet count: } \\
\hline$<150000 / \mu \mathrm{L}$ & 40/207 (19) & 2/42 (5) & 4.7 (1.1 to 20.2$)$ & t† & 2/41 (5) & 4.4 (1.0 to 19.2$)$ & t† \\
\hline $150000-450000 / \mu \mathrm{L}$ & 154/207 (74) & $36 / 42(86)$ & Reference & Reference & $34 / 41$ (83) & Reference & Reference \\
\hline$>450$ 000/pL & 13/207 (6) & 4/42 (9) & 0.8 (0.2 to 2.5$)$ & t† & $5 / 41(12)$ & $0.6(0.2$ to 1.7$)$ & t† \\
\hline
\end{tabular}

CRT=capillary refill time. 
Table 3 (continued)

\begin{tabular}{|c|c|c|c|c|c|c|c|}
\hline \multirow[b]{3}{*}{ Predictor } & \multirow{3}{*}{$\begin{array}{c}\text { Cases } \\
(\mathrm{n}=265)-\text { No } \\
(\%)\end{array}$} & \multicolumn{3}{|c|}{ Random controls $(n=265)$} & \multicolumn{3}{|c|}{ Age matched controls $(n=265)$} \\
\hline & & & Odds rati & $5 \% \mathrm{Cl})^{*}$ & & Odds rati & $5 \% \mathrm{Cl})^{*}$ \\
\hline & & No (\%) & $\begin{array}{c}\text { Univariable } \\
\text { analysis }\end{array}$ & $\begin{array}{c}\text { Multivariable } \\
\text { model }\end{array}$ & No (\%) & $\begin{array}{l}\text { Univariable } \\
\text { analysis }\end{array}$ & $\begin{array}{c}\text { Multivariable } \\
\text { model }\end{array}$ \\
\hline
\end{tabular}

*Random control results adjusted for site, age matched control results adjusted for site and age, using conditional logistic regression; for non-linear continuous predictor variables, effect reported as parameter estimates $(95 \% \mathrm{Cl})$ for linear, quadratic, and cubic terms.

†Not identified as significant in univariable analyses or in initial multivariable models.

$\ddagger$ Not identified as significant in final model.

$\S$ Estimate and $\mathrm{Cl}$ not calculated owing to non-prevalence in controls.

INot included in modelling process owing to prevalence in cases or controls $\leq 2 \%$.

${ }^{\star *}$ Heart rate term for final multivariable model includes adjustment for age (random control model odds ratio $0.8(95 \% \mathrm{Cl} 0.7$ to 0.9$)$; age matched control model odds ratio $1.4(95 \% \mathrm{Cl} 1.0$ to 1.9$))$

††Owing to reduced number of laboratory and radiographic investigations done in control groups, laboratory and radiographic investigation predictor variables were not included in multivariable analysis. 
Table 4| Emergency department management and outcome of children who developed severe outcomes with pH1N1 infection. Values are numbers (percentages) unless stated otherwise

\begin{tabular}{|c|c|c|c|}
\hline & Cases $(n=265)$ & WILIE group $(n=56)$ & Total $(n=321)$ \\
\hline \multicolumn{4}{|l|}{ Emergency department management } \\
\hline Admitted to hospital at initial presentation & $236(89)$ & $50(89)$ & $286(89)$ \\
\hline Admitted to ICU at initial presentation & $171(65)$ & $37(66)$ & $208(65)$ \\
\hline Intubated & $53(20)$ & $20(36)$ & $73(23)$ \\
\hline Oxygen & $219(83)$ & $48(86)$ & $267(83)$ \\
\hline Non-invasive ventilation $^{*}$ & $39(15)$ & $7(13)$ & $46(14)$ \\
\hline Invasive ventilation & $68(26)$ & $22(39)$ & $90(28)$ \\
\hline Intravenous fluid bolus & $168(63)$ & $36(64)$ & $204(64)$ \\
\hline Inotropic support & $39(15)$ & $6(11)$ & $45(14)$ \\
\hline Antibiotic treatment & $176(66)$ & $27(48)$ & $203(63)$ \\
\hline Antiviral treatment & $115(43)$ & $15(27)$ & $130(40)$ \\
\hline \multicolumn{4}{|l|}{ Subsequent management in hospital } \\
\hline Non-invasive ventilation & 130/261 (50) & $21(38)$ & $151 / 317(48)$ \\
\hline $\begin{array}{l}\text { Median (IQR) duration of non-invasive ventilation } \\
\text { (days) } \ddagger\end{array}$ & $2.0(0.7-3.8)$ & $1.1(0.8-2.0)$ & $2.0(0.7-3.6)$ \\
\hline Invasive ventilation & $147 / 261(56)$ & $36(64)$ & $183 / 317(58)$ \\
\hline $\begin{array}{l}\text { Median (IQR) duration of invasive ventilation } \\
\text { (days)§ }\end{array}$ & $6.4(3-12.7)$ & $5.8(2.3-10.8)$ & $6.1(2.9-12.3)$ \\
\hline Extracorporeal membrane oxygenation & $16(6)$ & $1(2)$ & $17(5)$ \\
\hline Inotropic support & 103/263 (39) & $16(29)$ & $119 / 319(37)$ \\
\hline Median (IQR) duration of inotropic support (days) $\mathbb{\top}$ & $2.8(1.4-6.0)$ & $3.3(2.2-7.8)$ & $3.0(1.5-6.0)$ \\
\hline Antibiotic treatment & $227 / 260(87)$ & $45(80)$ & $272 / 316(86)$ \\
\hline $\begin{array}{l}\text { Median (IQR) duration of antibiotic treatment } \\
\text { (days) }{ }^{\star *}\end{array}$ & $6.0(3.0-10.0)$ & $7.5(3.5-10.0)$ & $6.0(3.0-10.0)$ \\
\hline Antiviral treatment & $221 / 259(85)$ & $47(84)$ & $268 / 315(85)$ \\
\hline $\begin{array}{l}\text { Median (IQR) duration of antiviral treatment } \\
\text { (days)†† }\end{array}$ & $5.0(5.0-5.5)$ & $5.0(5.0-7.0)$ & $5(5.0-5.5)$ \\
\hline 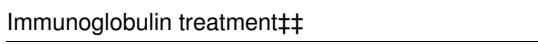 & $7 / 258(3)$ & $4(7)$ & $11 / 314(4)$ \\
\hline 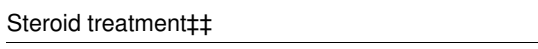 & $128 / 260(49)$ & $33(59)$ & $161 / 316(51)$ \\
\hline \multicolumn{4}{|l|}{ Outcome } \\
\hline Subsequent pneumonia after admission & $77 / 264(29)$ & $13 / 55(24)$ & $90 / 319(28)$ \\
\hline Acute respiratory distress syndrome§§ & $38 / 263(14)$ & $2 / 53(4)$ & $40 / 316(13)$ \\
\hline Secondary bacterial infection & 67/263 (25) & $15(27)$ & $82 / 319(26)$ \\
\hline Acute kidney injury/renal insufficiency & 22/263 (8) & 2/53 (4) & $24 / 316(8)$ \\
\hline Myocarditis & $11 / 262(4)$ & $1 / 53(2)$ & $12 / 315(4)$ \\
\hline Median (IQR) ICU length of stay (days) & $6(3-12)$ & $7(1-10)$ & $6.0(2.5-11.5)$ \\
\hline Median (IQR) hospital length of stay (days) & $9(5-18)$ & $11(4-16)$ & $9.2(4.7-17.7)$ \\
\hline Died & $27(10)$ & $7(13)$ & $34(11)$ \\
\hline
\end{tabular}

ICU=intensive care unit; IQR=interquartile range; WILIE=severe $\mathrm{H} 1 \mathrm{~N} 1$ without influenza-like illness in ED.

*Positive pressure ventilatory support not delivered via endotrachial tube, laryngeal mask airway (LMA), or surgical airway (that is, continuous positive airway pressure).

†Ventilatory support delivered via endotrachial tube, LMA, or surgical airway.

‡Data available for 76 (50\%) cases and WILIE patients.

§Data available for 96 (53\%) cases and WILIE patients.

IData available for 61 (51\%) cases and WILIE patients.

${ }^{* \star}$ Data available for $260(96 \%)$ cases and WILIE patients.

††Data available for 248 (96\%) cases and WILIE patients.

扭Treatment started either in emergency department or subsequently.

§§Defined as acute onset illness with $\mathrm{P}_{\mathrm{a}} \mathrm{O}_{2} / \mathrm{F}_{1} \mathrm{O}_{2}<200$ (if $\mathrm{P}_{\mathrm{a}} \mathrm{O}_{2}$ in $\mathrm{mm} \mathrm{Hg}$ ) or $<26.6$ (if $\mathrm{P}_{\mathrm{a}} \mathrm{O}_{2}$ in $\mathrm{kPa}$ ), bilateral diffuse chest radiograph opacities, absence of left sided heart failure or elevated left atrial pressure, and invasive or non-invasive ventilation for $>12$ hours. 
Table 5| Emergency department management and outcome in children who survived and died from severe pH1N1 infection. Values are numbers (percentages)

\begin{tabular}{|c|c|c|c|}
\hline & Died $(n=32)$ & Alive $(n=287)$ & $P$ value \\
\hline \multicolumn{4}{|l|}{ Emergency department management } \\
\hline Intubated & $8(25)$ & $63(22)$ & 0.69 \\
\hline Oxygen & $23(72)$ & $242(84)$ & 0.07 \\
\hline Non-invasive ventilation* & $4(13)$ & $42(15)$ & 0.74 \\
\hline Invasive ventilation $†$ & $8(25)$ & $80(28)$ & 0.73 \\
\hline Fluid bolus & $16(50)$ & $186(65)$ & 0.10 \\
\hline Inotropic support & $8(25)$ & $35(12)$ & 0.04 \\
\hline Antibiotic treatment & $17(53)$ & $186(65)$ & 0.19 \\
\hline Antiviral treatment & $7(22)$ & $123(43)$ & 0.02 \\
\hline \multicolumn{4}{|l|}{ Subsequent management in hospital } \\
\hline Non-invasive ventilation & $16 / 30(53)$ & $135 / 285(47)$ & 0.53 \\
\hline Invasive ventilation & $22(69)$ & $160 / 283(57)$ & 0.18 \\
\hline Extracorporeal membrane oxygenation & $7(22)$ & $10(3)$ & $<0.001$ \\
\hline Inotropic support & $20(63)$ & $98 / 285(34)$ & 0.002 \\
\hline Antibiotic treatment & $25 / 31(81)$ & $247 / 283(87)$ & 0.30 \\
\hline Antiviral treatment & $27(84)$ & $241 / 281(85)$ & 0.83 \\
\hline Immunoglobulin treatmentł & $3(9)$ & $8 / 280(3)$ & 0.06 \\
\hline Steroid treatment $\ddagger$ & $18(56)$ & $143 / 282(51)$ & 0.55 \\
\hline \multicolumn{4}{|l|}{ Outcome } \\
\hline Subsequent pneumonia after admission & $14(44)$ & $76 / 285(27)$ & 0.04 \\
\hline Acute respiratory distress syndrome§ & $10 / 31(32)$ & $30 / 283(11)$ & $<0.001$ \\
\hline Secondary bacterial infection & $14(44)$ & $68 / 285(24)$ & 0.01 \\
\hline Acute kidney injury/renal insufficiency & $8 / 31(26)$ & $16 / 283(6)$ & $<0.001$ \\
\hline Myocarditis & $5 / 31(16)$ & $7 / 282(2)$ & $<0.001$ \\
\hline
\end{tabular}

Data exclude two participants who arrived in emergency department in non-survivable cardiac arrest.

*Positive pressure ventilatory support not delivered via an endotrachial tube, laryngeal mask airway (LMA), or surgical airway (that is, continuous positive airway pressure).

†Ventilatory support delivered via endotrachial tube, LMA, or surgical airway.

¥Treatment started either in emergency department or subsequently.

§Defined as acute onset illness with $\mathrm{P}_{\mathrm{a}} \mathrm{O}_{2} / \mathrm{F}_{1} \mathrm{O}_{2}<200$ (if $\mathrm{P}_{\mathrm{a}} \mathrm{O}_{2}$ in $\mathrm{mm} \mathrm{Hg}$ ) or $<26.6$ (if $\mathrm{P}_{\mathrm{a}} \mathrm{O}_{2}$ in $\mathrm{kPa}$ ), bilateral diffuse chest radiograph opacities, absence of left sided heart failure or elevated left atrial pressure, and invasive or non-invasive ventilation for $>12$ hours. 